\title{
Inappropriate Prescription of Proton Pump Inhibitors in a Community Setting
}

\author{
Patrick Viet-Quoc Nguyen and Raja Tamaz
}

\begin{abstract}
Background: Proton pump inhibitors (PPIs) are widely prescribed for gastrointestinal conditions, such as gastroesophageal reflux disease and dyspepsia, and for prevention of gastric ulcer. Although previous reports have described inappropriate prescription of PPIs in the hospital setting, data from the community are lacking.

Objective: To assess PPI prescriptions in the ambulatory setting.

Methods: Patients presenting to the emergency department of a teaching hospital between June 2016 and March 2017 were prospectively assessed for use of a PPI at home. The appropriateness of PPI prescription was evaluated on the basis of an interview with the patient and review of the medical record. The indication for PPI therapy was verified against current guidelines for the province of Quebec.

Results: Over the 9-month study period, 2417 patients were screened, of whom 871 were included in the study. In relation to the Quebec guidelines, PPI prescription was inappropriate for 267 (30.7\%) of the patients. When prescription of PPI for ulcer prevention in certain groups of patients (age $\geq 65$ years and using acetylsalicylic acid or platelet aggregation inhibitors; age $\geq 75$ years and using celecoxib) was re-classified as appropriate, the proportion of inappropriate PPI prescriptions declined to $20.3 \%(177 / 871)$.

Conclusions: These findings suggest that inappropriate prescribing of PPIs remains problematic in the community setting in the province of Quebec.
\end{abstract}

Keywords: proton pump inhibitors, drug prescriptions, prescription drug misuse

Can J Hosp Pharm. 2018;71(4):267-71

\section{RÉSUMÉ}

Contexte : Les inhibiteurs de la pompe à protons (IPP) sont largement prescrits pour traiter les troubles gastro-intestinaux, comme le reflux gastro-œsophagien et la dyspepsie, et pour prévenir l'ulcère gastrique. Bien que des rapports antérieurs aient parlé de la prescription inadéquate des IPP dans les établissements de santé, il n’y a pas de données provenant de la communauté.

Objectif : Évaluer la pertinence des prescriptions d'IPP dans un milieu ambulatoire.

Méthodes : Les patients se présentant au service des urgences d'un hôpital universitaire entre juin 2016 et mars 2017 ont été évalués de façon prospective relativement à l'utilisation d'un IPP à la maison. La pertinence de la prescription d'un IPP a été jugée d'après une entrevue avec le patient et l'analyse du dossier médical. On a vérifié si l'indication pour un traitement par IPP respectait les lignes directrices actuelles du Québec.

Résultats : Sur une période de neuf mois, 2417 patients ont été évalués et 871 d'entre eux ont été admis à l'étude. Par rapport aux lignes directrices du Québec, la prescription d'IPP était inadéquate pour 267 (30,7 \%) des patients. Or, si la prescription d'IPP pour prévenir l' ulcère gastrique chez certains groupes de patients (âgés de 65 ans ou plus et prenant de l'acide acétylsalicylique ou un antiagrégant plaquettaire; âgés de 75 ans ou plus et prenant du célécoxib) était reclassée comme adéquate, la proportion de prescriptions d'IPP inadéquates reculait à 20,3\% (177/871).

Conclusions : Ces résultats laissent croire que les prescriptions inadéquates d'IPP demeurent un problème dans le contexte communautaire au Québec.

Mots clés : inhibiteurs de la pompe à protons, prescriptions de médicaments, mauvais emploi d'un médicament d'ordonnance 


\section{INTRODUCTION}

$\mathrm{P}$ roton pump inhibitors (PPIs) are widely prescribed acid suppressant drugs. In 2015, PPI prescriptions accounted for $\$ 253.3$ million in public drug program spending in Canada. ${ }^{1}$ These drugs tend to be used for long periods for the treatment of chronic conditions such as gastroesophageal reflux disease (GERD) and dyspepsia, or for the prevention of gastric ulcers in people who are taking nonsteroidal anti-inflammatory drugs (NSAIDs). ${ }^{2}$ However, the safety of long-term PPI use remains controversial. PPIs have been associated with increased risk of various adverse effects such as kidney disease, pneumonia, Clostridium difficile infection, fracture, and hypomagnesemia. ${ }^{3}$ Recently, an increased risk of death was reported for PPI use relative to no PPIs, with a hazard ratio of 1.15 (95\% confidence interval [CI] 1.14-1.15). ${ }^{4}$

Previous publications have described inappropriate prescription of PPIs. The recent literature (2012-2015) reported rates of inappropriate prescribing that ranged from $19 \%$ to $86 \% .^{5-13}$ However, all but 2 of these reports involved retrospective chartbased studies. Since the indication for PPI use may not be rigorously documented in patient charts, use of this type of study design may have led to overestimation of inappropriate prescribing. Differences in usage criteria, practice guidelines, study populations, and local medical practices may also explain the wide range in reported prevalence of inappropriate PPI prescriptions. Moreover, all of these studies were carried out in a hospital setting, such that they mainly described PPI prescription patterns by hospital physicians for inpatients. Appropriateness of PPI prescribing in the community setting has been addressed by only a few investigators. ${ }^{14,15}$ Recent data for this setting, especially in the Canadian population, are still lacking.

The objective of this study was to document the prevalence of inappropriate PPI prescriptions in an ambulatory population.

\section{METHODS}

This prospective cross-sectional study was performed in the emergency department of the Centre hospitalier de l'Université de Montréal (CHUM) in Montréal, Quebec. This institution is a multispecialty tertiary care teaching hospital spread over 3 physical locations, each with its own emergency department. Eligible patients were adults presenting to any of the 3 emergency departments and taking a PPI at home at the time of admission. Using the list of patients registered in the emergency department computer system, research assistants identified all potential PPI users from information recorded in the Quebec Health Record or available from the institution's outpatient pharmacy or from long-term care home medication lists. The Quebec Health Record is a computerized medical record for all patients in the province of Quebec, which documents clinical information and prescription drugs.
Screening was done on weekdays, during regular working hours, from June 20, 2016, to March 29, 2017. To further ascertain outpatient use of PPIs, patients were interviewed during their stay in the emergency department. Patients who initiated a PPI during their visit to the emergency department and those who were readmitted over the study period were excluded. The data were collected using medical and nursing observation sheets in patient charts and the patient interview. Demographic data were age, sex, and reason for the consultation. PPI data recorded were the indication for PPI treatment or prophylaxis, the type of PPI, and the dose and dosage regimen. The duration of PPI therapy was assessed for all PPI indications. The indication for PPI prescription was identified through patient inquiry, review of clinical notes, and previous hospital medical records. Medical data included the gastrointestinal medical history, as well as medical history related to neurologic, psychiatric, cardiovascular, pulmonary, nephrologic, endocrinologic, and rheumatologic conditions, and to chronic kidney failure and cancer. Concomitant use of NSAIDs, oral and parenteral anticoagulants, steroids, platelet aggregation inhibitors, and selective serotonin reuptake inhibitors (SSRI) was also determined.

PPI prescriptions were compared with the guideline published by the Conseil des médicaments (now incorporated within the Institut national d'excellence en santé et en services sociaux [INESSS]), published in 2010. ${ }^{2}$ The mission of the INESSS is to promote clinical excellence and the efficient use of health resources. PPI prescriptions were considered appropriate if dyspepsia, GERD, Zollinger-Ellison syndrome, or esophagitis secondary to GERD was present. The use of a PPI was considered appropriate if the duration of therapy was 8 weeks following diagnosis of ulcer or 4 months for Helicobacter pylori infection. PPI for ulcer prophylaxis in patients using NSAIDs was considered appropriate under the following conditions:

- presence of one or more of the following risk factors: age 75 years or older; history of peptic ulcer; use of warfarin, heparin (unfractionated and low molecular weight), or direct oral anticoagulants

- presence of 2 or more of the following risk factors: age 6574 years; comorbid diseases (arthritis, diabetes mellitus, or cardiovascular disease); use of steroids, acetylsalicylic acid (ASA), platelet aggregation inhibitors, or SSRI.

Patients using low-dose ASA were not considered to be NSAID users. The use of PPI for ulcer prophylaxis in patients 65 years or older who are taking ASA or platelet aggregation inhibitors and in patients 75 years or older who are taking celecoxib without other risk factors remains controversial. Use of PPI in these patients was not considered "appropriate" for purposes of the main analysis, because these indications are not mentioned in the INESSS guidelines; however, they were analyzed separately.

Continuous and categorical variables were described using means and proportions, respectively. Analyses were performed 
using SPSS 24 (IBM, Armonk, New York). The study protocol was approved by the CHUM research ethics board. Verbal consent was required and obtained before each patient interview.

\section{RESULTS}

During the 9-month study period, 2417 patients were screened, of whom 1458 were not taking a PPI at home before their visit to the emergency department and 24 were unable to answer the survey. Of the remaining 935 patients who met the inclusion criteria, 64 refused to participate; therefore, 871 patients were included in the study. The mean age \pm standard deviation was $68 \pm 15$ years, and 476 (54.6\%) of the patients were women. Comorbid conditions identified in the study population are listed in Table 1. The most common reasons for medical consultation in the emergency department were shortness of breath (105, $12.1 \%)$, gastrointestinal pain $(78,9.0 \%)$, general deterioration $(69,7.9 \%)$, pain other than gastrointestinal $(97,11.1 \%)$, and infection (44, 5.1\%).

Characteristics of PPI use in the study population are reported in Table 2. A total of 769 patients (88.3\%) took their PPI once daily, 101 patients (11.6\%) took their PPI twice daily, and 1 patient took the PPI three times daily. The most common indication for a PPI prescription reported during the patient interview was "heartburn" ( $n=247$ patients), followed by ulcer prophylaxis $(n=220)$, GERD $(n=170)$, dyspepsia $(n=51)$, and gastric ulcer therapy $(n=38) ; 123$ patients did not know the

\section{Table 1. Medical Characteristics of the Study Population}

$\begin{array}{lrc}\text { Medical History* } & \text { No. (\%) of Patients } \\ \text { ( } \boldsymbol{n}=\mathbf{8 7 1 )}\end{array}$

indication for their PPI prescription, and 22 had other indications. In addition to the PPI therapy, an SSRI was prescribed for 113 patients (13.0\%), steroids for 154 patients (17.7\%), NSAIDs for 63 patients (7.2\%), and platelet aggregation inhibitors for 67 patients $(7.7 \%)$. Direct oral anticoagulants, warfarin, and parenteral anticoagulants were prescribed for 101 (11.6\%), $66(7.6 \%)$, and $28(3.2 \%)$ patients, respectively.

Overall, for 604 patients (69.3\%), the PPI was prescribed for an appropriate indication. Some patients had more than 1 appropriate indication for the PPI prescription (Table 3). No patient was taking a PPI for Zollinger-Ellison syndrome. When the controversial indications for PPI prescriptions were counted as appropriate, the incidence of appropriate prescription was 694 patients $(79.7 \%)$. Some patients had more than 1 controversial indication for the PPI prescription. No patient aged 65 to 74 years had a prescription for NSAID therapy without any other risk factor.

The mean age of patients with inappropriate PPI prescription was significantly higher than the age of patients with appropriate

\section{Table 2. Characteristics of Prescriptions for Proton Pump Inhibitor (PPI)}

\begin{tabular}{lrcc} 
PPI & No. (\%) of Patients & $\begin{array}{c}\text { Median Total Daily } \\
\text { Dose (mg) }\end{array}$ \\
\hline Pantoprazole & $626(71.9)$ & 40 \\
Deslansoprazole & $139(16.0)$ & 60 \\
Esomeprazole & 50 & $(5.7)$ & 40 \\
Lansoprazole & 30 & $(3.4)$ & 30 \\
Omeprazole & 21 & $(2.4)$ & 20 \\
Rabeprazole & 5 & $(0.6)$ & 20 \\
\hline
\end{tabular}

Table 3. Appropriate Prescription of Proton Pump Inhibitors

\begin{tabular}{lrr} 
Indication & No. (\%) of Patients \\
\hline Appropriate indications* & 470 & $(54.0)$ \\
Gastroesophageal reflux & 282 & $(32.4)$ \\
Dyspepsia & 105 & $(12.1)$ \\
Esophagitis & 15 & $(1.7)$ \\
Ulcer & 5 & $(0.6)$ \\
$\quad$ Positive for Helicobacter pylori & 20 & $(2.3)$ \\
Ulcer prophylaxis & & \\
\hline Controversial indicationst & 82 & $(9.4)$ \\
Ulcer prophylaxis in patient $\geq 65$ years & & \\
who is taking ASA & 5 & $(0.6)$ \\
Ulcer prophylaxis in patient $\geq 75$ years & 18 & $(2.1)$ \\
who is taking celecoxib & & \\
Ulcer prophylaxis in patient $\geq 65$ years & \\
who is taking platelet aggregation inhibitor & \\
ASA = acetylsalicylic acid. & \\
*Some patients had more than 1 appropriate indication for a proton \\
pump inhibitor. \\
tSome patients had more than 1 controversial indication.
\end{tabular}


PPI therapy, with a difference of 3.8 years (95\% CI 1.6-6.0 years). A higher proportion of patients with a history of psychiatric disease had an appropriate PPI prescription regimen. Neurologic, cardiovascular, and pulmonary comorbid diseases and patients' sex were not associated with inappropriate PPI prescribing.

\section{DISCUSSION}

The appropriate use of PPIs has been studied in the hospital setting in various studies, but only a few authors have addressed the prescribing of PPIs in the community setting. In 2007, Batuwitage and others ${ }^{14}$ published their prospective assessment of PPI indications in 66 patients, reporting that PPI therapy was appropriate for 30 patients (46\%), according to guidelines of the UK National Institute for Health and Care Excellence (NICE). In a retrospective study, Heidelbaugh and others ${ }^{15}$ evaluated 946 patients with a PPI prescription, of whom 341 (36.1\%) did not have an appropriate indication.

Overall, this study found a $30.7 \%$ incidence of inappropriate PPI prescriptions in the community setting, according to the INESSS practice guidelines; the incidence was $20.3 \%$ if controversial indications were considered appropriate. These findings suggest that inappropriate prescribing of PPIs remains problematic in the community setting in the province of Quebec, despite the publication, in 2010, of guidelines concerning the use of PPIs from the INESSS (formerly the Conseil des médicaments), an agency of the Quebec health ministry. ${ }^{2}$

The difference between the current results and those of Batuwitage and others ${ }^{14}$ can be explained by our consideration of PPI prescriptions for all patients with dyspepsia as appropriate, whereas the NICE guideline accepted PPI therapy for this condition only if the duration was 1 month and the dyspepsia had not been investigated. The lower rate of inappropriate PPI prescribing in the current study relative to that of Heidelbaugh and others ${ }^{15}$ may be attributed to our prospective study design, which allowed more accurate detection of gastrointestinal diseases through patient interviews.

For one of our analyses, we defined PPI therapy for controversial indications as appropriate. Despite the absence of clear guidelines on PPI use for these controversial indications, recent evidence has shown the efficacy of PPIs in the prevention of gastrointestinal events, especially for the elderly population. In a study published in 2013, Hedberg and others ${ }^{16}$ compared the risk of gastrointestinal ulcers and bleeding in patients using low-dose ASA with and without PPI. The hazard ratio was 1.14 (95\% CI 1.05-1.23) for the group not taking PPI relative to the continuous PPI users, who had high adherence. Rahme and others ${ }^{17}$ studied the risk of hospital admission for a gastrointestinal problem among patients taking celecoxib with and without a PPI. Overall, there was no significant difference between the 2 groups. However, in a subgroup analysis, the authors detected a reduction of events in elderly patients (75 years and older) using celecoxib and a PPI; the hazard ratio was $0.56(95 \%$ CI $0.38-0.81)$ relative to those not taking a PPI. Hsu and others ${ }^{18}$ studied the incidence of recurrent peptic ulcer in patients using clopidogrel with and without esomeprazole and found a statistically significant difference favouring the combination therapy.

One strength of the current study was that patients were recruited prospectively, which allowed us to collect more accurate data on patients' medical history and indication for PPI therapy. Inclusion of patients who were not actually taking PPIs was avoided by directly questioning potential participants about their PPI use. In contrast, a retrospective study might have included patients who had a PPI prescription but were not actually taking the drug.

This study also had limitations. The study design did not permit systematic recruitment of patients arriving in the emergency department. Patients who arrived for consultation during the evening, at nighttime, and on weekends may have left without being screened for this study, which increased selection bias. However, this bias was reduced by collecting the data over a 9-month period and performing the analyses on a large sample. Young patients may visit the emergency department outside of regular working hours, which might explain the high mean age of study participants. A prescription for PPI may not necessarily reflect prescribing practices of the hospital's medical staff, since the PPI prescriptions for many of the included patients were dispensed in the ambulatory setting. The results related to PPI prescribing patterns may reflect the larger Montréal region, rather than the vicinity of the hospital centre. Because the study took place in a single health centre, the results may not be generalizable to the province or the country. Similarly, because the study included only patients visiting the emergency department, the results may not be generalizable to the entire ambulatory population. Nonetheless, PPI prescribing guidelines are the same across the province, and these provincial guidelines are very similar to national and international guidelines, so it may be reasonable to extrapolate the results to a larger population.

Despite the use of patient interviews and a medical chart review, it is possible that some medical data were missing because of memory bias or data missing from the charts. The indication for PPI use was determined in part from the patient interview, but patients may report gastric disease not based on a medical diagnosis, which may also lead to overestimation of appropriate PPI prescriptions. The cross-sectional design impeded accurate estimation of PPI use over time, and data on drug use was not available from the insurer database. Hence, the time since diagnosis of gastric ulcer and the duration of PPI use were estimated by the patient, which could lead to misclassification of appropriateness. The provincial guideline suggests initial PPI therapy for 4 weeks for uninvestigated dyspepsia with or without GERD for symptoms that are present at least 3 days/week. Long-term PPI therapy must be re-evaluated and continued only 
if the dyspepsia symptoms persist. Adherence with this recommendation could not be assessed in this study. The lack of evaluation of PPI use over time, and the lack of data on medical follow-up may have led to overestimation of appropriate PPI prescriptions. Patients' compliance with prescribed therapy was not evaluated in the current study but could be an interesting topic for further investigations.

In addition to safety concerns related to inappropriate prescribing of PPIs, the economic burden to the health care system is substantial. According to the INESSS, the monthly cost of PPI prescriptions in March 2014 was $\$ 8.9$ million, ${ }^{19}$ or an estimated annual cost of about $\$ 106.8$ million. Using the rates determined in the current study, $\$ 21.7$ million to $\$ 32.8$ million of this total may relate to inappropriate PPI prescribing. Furthermore, this amount does not take into account patients with private insurance coverage, so the true cost may be greater.

\section{CONCLUSION}

Inappropriate prescription of PPIs remains high, despite the existence of guidelines and even when controversial indication criteria were counted as appropriate. Inappropriate prescribing of PPIs may expose patients to adverse reactions such as hypomagnesemia, pneumonia, and fractures. Inappropriate prescribing also carries substantial financial costs.

\section{References}

1. Prescribed drugs spending in Canada, 2016. Ottawa (ON): Canadian Institute for Health Information.; 2016 [cited 2017 July 31]. Available from: https://secure.cihi.ca/free_products/Prescribed\%20Drug\%20Spending\%20i n\%20Canada_2016_EN_web.pdf.

2. Principes d'usage optimal des inhibiteurs de la pompe à protons (IPP). Québec (QC): Conseil du médicament; 2010 [cited 2017 Jul 31]. Available from: https://www.inesss.qc.ca/fileadmin/doc/CDM/UsageOptimal/ AINS-IPP/CdM-Principes-IPP.pdf

3. Schoenfeld A, Grady D. Adverse effects associated with proton pump inhibitors. JAMA Intern Med. 2016;176(2):172-4.

4. Xie Y, Bowe B, Li T, Xian H, Yan Y, Al-Aly Z. Risk of death among users of proton pump inhibitors: a longitudinal observational cohort study of United States veterans. BMJ Open. 2017;7(6):e015735.

5. Redfern RE, Brown M, Karhoff KL, Middleton JL. Overuse of acidsuppression therapy at an urban tertiary hospital. South Med J. 2015; 108(12):732-8.

6. Kelly OB, Dillane C, Patchett SE, Harewood GC, Murray FE. The inappropriate prescription of oral proton pump inhibitors in the hospital setting: a prospective cross-sectional study. Dig Dis Sci. 2015;60(8):2280-6.

7. Bergamo D, Pastorino A, Greppi F, Versino E, Bo M, D’Amelio P, et al. Inappropriate proton pump inhibitor prescription in elderly adults: as usual as dangerous. J Am Geriatr Soc. 2015;63(10):2198-9.

8. Moran N, Jones E, O'Toole A, Murray F. The appropriateness of a proton pump inhibitor prescription. Ir Med J. 2014;107(10):326-7.

9. Chia CT, Lim WP, Vu CK. Inappropriate use of proton pump inhibitors in a local setting. Singapore Med J. 2014;55(7):363-6.

10. Albugeaey M, Alfaraj N, Garb J, Seiler A, Lagu T. Do hospitalists overuse proton pump inhibitors? Data from a contemporary cohort. $J$ Hosp Med. 2014;9(11):731-3.
11. Leri F, Ayzenberg M, Voyce SJ, Klein A, Hartz L, Smego RA Jr. Four-year trends of inappropriate proton pump inhibitor use after hospital discharge. South Med J. 2013;106(4):270-3.

12. Jarchow-Macdonald AA, Mangoni AA. Prescribing patterns of proton pump inhibitors in older hospitalized patients in a Scottish health board. Geriatr Gerontol Int. 2013;13(4):1002-9.

13. Reid M, Keniston A, Heller JC, Miller M, Medvedev S, Albert RK. Inappropriate prescribing of proton pump inhibitors in hospitalized patients. J Hosp Med. 2012;7(5):421-5.

14. Batuwitage BT, Kingham JGC, Morgan NE, Bartlett RL. Inappropriate prescribing of proton pump inhibitors in primary care. Postgrad Med J. 2007;83(975):66-8.

15. Heidelbaugh JJ, Goldberg KL, Inadomi JM. Magnitude and economic effect of overuse of antisecretory therapy in the ambulatory care setting. $\mathrm{Am} \mathrm{J}$ Manag Care. 2010;16(9):e228-34.

16. Hedberg J, Sundström J, Thuresson M, Aarskog P, Oldgren J, Bodegard J. Low-dose acetylsalicylic acid and gastrointestinal ulcers or bleeding--a cohort study of the effects of proton pump inhibitor use patterns. J Intern Med. 2013;274(4):371-80.

17. Rahme E, Barkun AN, Toubouti Y, Scalera A, Rochon S, Lelorier J. Do proton-pump inhibitors confer additional gastrointestinal protection in patients given celecoxib? Arthritis Rheum. 2007;57(5):748-55.

18. Hsu PI, Lai KH, Liu CP. Esomeprazole with clopidogrel reduces peptic ulcer recurrence, compared with clopidogrel alone, in patients with atherosclerosis. Gastroenterology. 2011;140(3):791-8. Erratum in: Gastroenterology. 2011;141(2):778.

19. Jehanno C, Baril J, Chamberland C. Suivi de la mesure de remboursement des inhibiteurs de la pompe à protons (IPP). Québec (QC): Institut national d'excellence en santé et en services sociaux; 2014 [cited 2017 Jul 31]. Available from: https:/www.inesss.qc.ca/fileadmin/doc/INESSS/Rapports/Medicaments/ INESSS_Suivi_de_la_mesure_de_remboursement_des_IPP.pdf

Patrick Viet-Quoc Nguyen, MSc, is with the Centre hospitalier de I'Université de Montréal Research Centre and the Réseau québécois de recherche en vieillissement, Montréal, Quebec.

Raja Tamaz, MD, is with the Hôpital Sacré-Cœur de Montréal, Montréal, Quebec.

Competing interests: None declared.

\section{Address correspondence to:}

Patrick Viet-Quoc Nguyen

Centre hospitalier de I'Université de Montréal

1000, rue Saint-Denis

Montréal QC H2X OC1

e-mail: patrick.nguyen@umontreal.ca

Funding: None received.

Acknowledgements: The authors would like to thank Stephanie Patenaude, Jean-Philip Monette, Thomas Cejudo, Camille Fonsale, and Elise Carteron for their contributions to data collection and analysis for this study. 